\title{
VIEWPOINT
}

\section{Why Mobility Justice Means Prioritising Accessible Walking Environments}

\author{
Caroline Mullen \\ University of Leeds, UK \\ c.a.mullen@leeds.ac.uk
}

\begin{abstract}
Promotion of active travel is a fixture in transport policy and planning. Yet, this paper argues, walking and the availability of comprehensive and accessible pedestrian environments have an importance for mobility justice and sustainability which is not currently recognised. The paper investigates how and why walking provision matters for justice, and explores what this means for decision-making affecting mobility systems and the built environment. It begins with an argument that a coherent conception of mobility justice would be simultaneously concerned with environmental and social implications of transport since both affect people's physical lives, welfare and flourishing. That requirement frames the types of mobility systems which could be compatible with justice, and points to a need for prioritisation of active travel far beyond current policy and practice. Specifically, the need for environmental sustainability coupled with social inclusion creates a case for systematically prioritising provision for walking over other mobility. This means the removal of all forms of barriers to walking so that no one is excluded by severance, impassable surfaces or lack of safety.
\end{abstract}

Keywords: walking; severance; mobility justice; inclusion; environmental sustainability; accessibility

\section{Introduction}

Walking is persistently present in policy and discourse on sustainable mobility although progress on increasing walking (and active travel) is patchy (e.g. Pooley et al., 2013). Conditions for walking, including movement around neighbourhoods, are also the subject of some work on social inclusion in transport planning and policy. For instance, there is consideration of the difficulties faced by people whose only travel mode is walking and who need to walk through areas which are polluted or dangerous (for instance, Bostock, 2001; Figueroa Martínez et al., 2019). Further work has considered the impacts of community severance where traffic is itself a barrier to movement and so to community interaction Mindell and Saffron, 2012). There is also research on accessible walking environments which do not exclude people with disabilities or mobility difficulties (e.g. Eisenberg et al., 2017). However, this work is somewhat disparate, treating separately a range of problems associated with different aspects of the walking environment. 
I argue, in this paper, that prioritising accessible walking environments is necessary for mobility justice and by extension for sustainable mobility. The term "accessibility" here should be understood as conditions in which, to the greatest extent possible, anyone is able to move around safely on foot or by using a wheelchair, mobility scooter or other aids to walking. "Walking" can be understood as a travel mode (e.g. travel to work) but can also be very localised movement, such as around a person's immediate neighbourhood. I discuss how this argument has far-reaching implications for the treatment of walking environments in transport policy and planning. This is not just a case of giving more attention to pedestrian environments or setting ambitions to increasing levels of walking - although it does include both points. It is an argument about priorities in decision-making where there is competition between attention to the walking environment and other factors such as provision for vehicular traffic, and so it is an argument about the criteria used to determine the value of resources and opportunity costs devoted to improving the walking environment.

The next section discusses the normative ideas underpinning mobility justice, and section 3 outlines the scope of concerns for mobility justice. This provides the basis for the investigation of how and why focusing on conditions for active travel, and specifically for walking, are essential in creating a just mobility system.

\section{Normative grounding of mobility justice}

Work on mobility or transport justice faces theoretical as well as practical questions and challenges. A brief discussion of these theoretical aspects is needed to understand the rationale underpinning the central argument on walking and mobility justice. One challenge has been for normative ideas of justice to be recognised as an organising principle for transport planning and policy. The issue is not that transport planning or policy has operated independently of normative ideas. Relatively longstanding and established approaches in transport, such as cost benefit analysis, are grounded in a version of utilitarian moral theory (Beyazit, 2011). The issue is that explicitly moral or normative critiques of this approach to transport, along with investigations of alternative normative approaches, are still less well established. That may be slowly changing with an expansion in normative critiques of transport and decision-making in transport, including work on mobility justice (for instance, Beyazit, 2011; Martens, 2016; Mattioli, 2016; Mullen and Marsden, 2016; Verlinghieri and Schwanen, 2020). However overcoming this challenge is an ongoing process with significance for efforts to integrate justice into practises of transport policy and planning, and one aim for this paper is to contribute to that effort.

The second challenge is in determining what normative ideas or theoretical approaches to adopt in investigations of mobility justice. This challenge has substantive and procedural aspects, and for reasons of scope it is only substantive aspects which are considered in this paper. Theories of justice have developed over thousands of years, often in opposition to each other (for instance, see discussion in Mullen and Marsden, 2016; Verlinghieri and Schwanen, 2020). So work on mobility justice involves a non-obvious decision about its normative basis. For work primarily concerned with application rather than theory of mobility justice, there is a practical question of how to give sufficient justification of the normative approach used. Leaving the theoretical or conceptual questions aside altogether risks a loss of transparency and potentially an increased risk of unchecked implicit bias. It also removes a major method of testing the coherence of arguments about what justice means in practise (a similar approach is used elsewhere; see for instance, Dworkin, 2000; Harris, 1998).

In this paper the approach taken is to begin from basic normative assumptions which under-determine any one theory (see Mullen and Marsden, 2016). These assumptions are consistent with a broad range of theoretical and conceptual approaches to substantive and procedural justice, which include capabilities approaches, virtue ethics and ethics of care, 
communitarian approaches, needs-based approaches, some consequentialist egalitarian theories and some deliberative, participatory and democratic approaches. These assumptions are set out in Figure 1.

By beginning with assumptions about the (moral) importance of people, we help ground investigations of mobility or transport justice in processes of considering why and how mobility and mobility systems matter to (different) people and people are affected by mobility systems. Grounding can help in identifying procedural and substantive questions and challenges for questions for mobility or transport justice. We can then consider what theoretical or conceptual approaches might be capable of coherently addressing these challenges. Beginning with a more fully specified theory might obscure relevant challenges if that theory has a priori determined how substantive (e.g. resource allocation) or procedural questions should be treated. As noted above, the plausibility of a theory can be tested through application. If, for instance, the theory cannot coherently tackle applied problems, then we can look elsewhere for a theory that might be more plausible. This, however, is a longer route to the same position of considering what theoretical approaches can solve problems raised by mobility. There are reasons why this longer route could be preferable as it implies a deeper analysis of the initial theory and its application. However, this is not a feasible within the scope of a short paper.

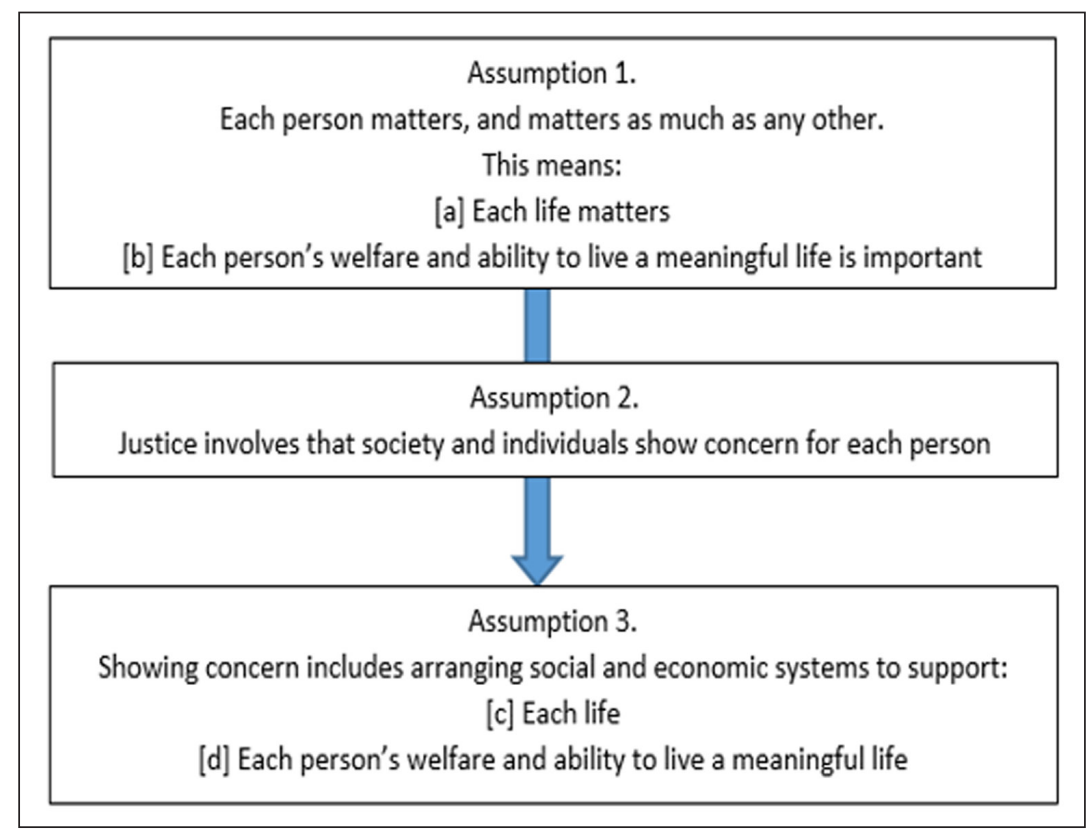

Figure 1: Normative assumptions for Justice.

Notes:

i. The terms 'matter' and important' here are taken as meaning morally significant.

ii. These assumptions concern people, but do not exclude moral significance for other beings organisms or environment that also have intrinsic moral value.

iii. These assumptions recognise the importance of basic survival but also the diversity of activities, aims, plans which are important to people. The assumptions are neutral about what constitutes a 'meaningful' life, or how that is decided, and it is recognised that different theories will take different positions on these questions. 
Before moving on to questions of the application of these normative assumptions, it is worth making a brief note on terminology. There is some debate over the use of the terms "transport justice" and "mobility justice." For instance, Verlinghieri and Schwanen (2020) make use of the terms as codifiers in describing various strands of research in this area. This paper tends to use the term "mobility justice" for two reasons. First (and this is shown in the next section), the present argument is that environmental as well as social and economic implications of mobility are central to the questions of justice in this area, a position that has not always been taken in work using the term "transport justice" (ibid.). Second, we are concerned with often very localised movement, and in its common usage "transport" may not be understood as including this movement.

\section{Scope of mobility justice}

Mobility systems have multiple direct and indirect implications for lives, wellbeing and for the ability to live a meaningful life. If the first two normative assumptions are accepted, then justice requires that we seek to arrange transport (as part of our social and economic system) in a way that takes account of these multiple implications as they affect each person.

Many of these individual implications of transport will be familiar, but since it is the set taken together which matters for justice, it is worth giving an indication of the scope of that set. As mobility systems currently exist in most jurisdictions, there is reliance on high levels of motor vehicles with varying levels of transition to vehicles which are zero emission at tailpipe (see e.g. Brand et al., 2020; Sims et al., 2014). Transport remains a major problem for efforts to decarbonise and so is contributing to the impacts of climate change on people through drought, flooding and other aspects of harm to the eco-system (Rogelj et al., 2018). Transitions to electric and hydrogen vehicles are expected to make the major contribution to transport decarbonisation, but there is evidence that this transition will not be sufficient and that reduction in motor vehicle travel is also required. The International Energy Agency (2017) estimate that for compliance with the Paris Agreement, 20\% of decarbonisation needs to come from mode shift and demand reduction. Motor vehicles are also responsible for poor air quality, through pollution including $\mathrm{NO}_{2}$ and particulate matter. Over a million deaths each year are attributed to outdoor pollution and while not accounting for all that pollution, traffic is a major source (WHO 2016). While vehicles which are zero emission at tailpipe present less of a problem for outdoor pollution, they still create particulate matter through tyres and brakes (Grigoratos and Martini, 2014). Traffic and land use taken for transport have detrimental effects on flora and fauna through surface pollution and fragmentation (EEA, FOEN 2011; Karlson and Mörtberg, 2015). This contributes to pressures on biodiversity and also on what is called the "safe" operating space for humanity (Mace et al., 2014). Road traffic collisions kill about 1.3 million people worldwide each year with pedestrians and cyclists suffering disproportionally compared to occupants of cars (WHO, 2018).

There are complex interactions between ability to travel, or move around an area, and ability to participate in social, economic and other activities. Availability, affordability and accessibility of mobility can determine what economic, educational and social activities are viable for different people (see e.g. Mullen, Marsden and Philips, 2020; Preston and Raje, 2007). Yet the travel required for different activities is not always something which is fixed. It can be influenced by factors including the wider mobility system, especially if that system privileges some forms of mobility over others. Specifically, in mobility systems where there are high levels of motor traffic, households can struggle to participate in everyday activities without access to a vehicle (Mattioli, 2017). It can also be shaped by other systems, including those impacting on where people live, work and engage in other activities (Mullen, Marsden and Philips, 2020).

If each person matters, then mobility justice involves reducing the harms caused by transport, and because everyone matters equally, justice means reducing health inequalities and 
inequalities in exposure to harm. Mobility justice also means simultaneously enabling people to have mobility they need to live, and to live a meaningful life. There is not enough space here to explore questions about different conceptions of "meaningful" and levels and forms of mobility required by different people for that "meaningful" life to be realised. What we can note is that those levels and types of mobility will be bounded by requirements to reduce harm and inequalities in harm caused by mobility. It will also be bounded by a requirement that mobility for some groups does not create transport related exclusion for others.

\section{Practical implications of mobility justice}

At a high level, it is not difficult to see that the types of changes to the mobility system which will support mobility justice appear very similar to those which have been long recognised as central to sustainable transport. What matters for justice, however, is the detail of how these measures work, and it is in thinking through this detail that we see the case for prioritising the walking environment.

If we look only at the justice requirement to minimise the harm to life and health caused by high levels of motor traffic, then it would make sense to focus on doing as much as is feasible to support a shift from travel by conventional cars to active travel. This aspect of justice is also likely to be supported by encouraging greater use of public transport, although there will be caveats about emissions from public transport and potential that some public (or shared) transport might contribute to increasing overall demand for vehicular travel (e.g. Mullen, 2020; Wadud, MacKenzie and Leiby, 2016). Uptake of cleaner vehicles will contribute to reducing some of the harms of traffic, in particular those associated with $\mathrm{CO}_{2}$ emissions and poor air quality. However, simply replacing conventional with low emissions vehicles will not tackle road traffic collisions, severance or habitat fragmentation.

We have evidence about the sorts of measures which encourage more active travel, particularly reducing pedestrians' and cyclists' exposure to risks from other traffic (e.g. Pooley et al., 2013; Yang et al., 2020). This is recognised (even if not always practised) in policy as well as by researchers (e.g. DfT (a) 2020). In this context it may not matter whether it is cycling or walking which is given most attention in policy and planning. It may also not matter if some people rarely walk, and perhaps never cycle. What would matter more is the scale of shift away from motor traffic across the whole population.

Yet when we consider justice requirements to prevent transport related exclusion alongside requirements of minimising harm and inequality in harm, the picture becomes more complicated. To see this, we can consider two questions. The first concerns reasons that can prevent people from making a journey (or a leg of a multi-modal journey) on foot or by bicycle, when all things being equal, they would be physically able to do so. The second concerns the implications for justice when people are prevented from walking or cycling in this way.

The first question brings to the fore the many forms that poor walking and cycling conditions can take. Perhaps most prominent, and already noted, are walking and cycling routes which expose people to risks from traffic and can act as a partial or complete barrier to walking or cycling, preventing both even where the risk only occurs on a small part of the journey. For instance, it could be a section of road or junction or crossing that someone considers too dangerous to navigate. Barriers can also be created by crime, or fear of crime (Figueroa Martínez et al., 2019), and again, it might be only a small part of the route that is considered too dangerous. A third form of barrier are physical obstructions, including those which mean it is impossible (or at least impossible for some people) to get over or through, and surface conditions which make a route impassable for some or all people. Figure $\mathbf{2}$ is an example of surface conditions which are inaccessible to people unable to use steps, and in this case an entire route between towns requires that pedestrians use the steps. 


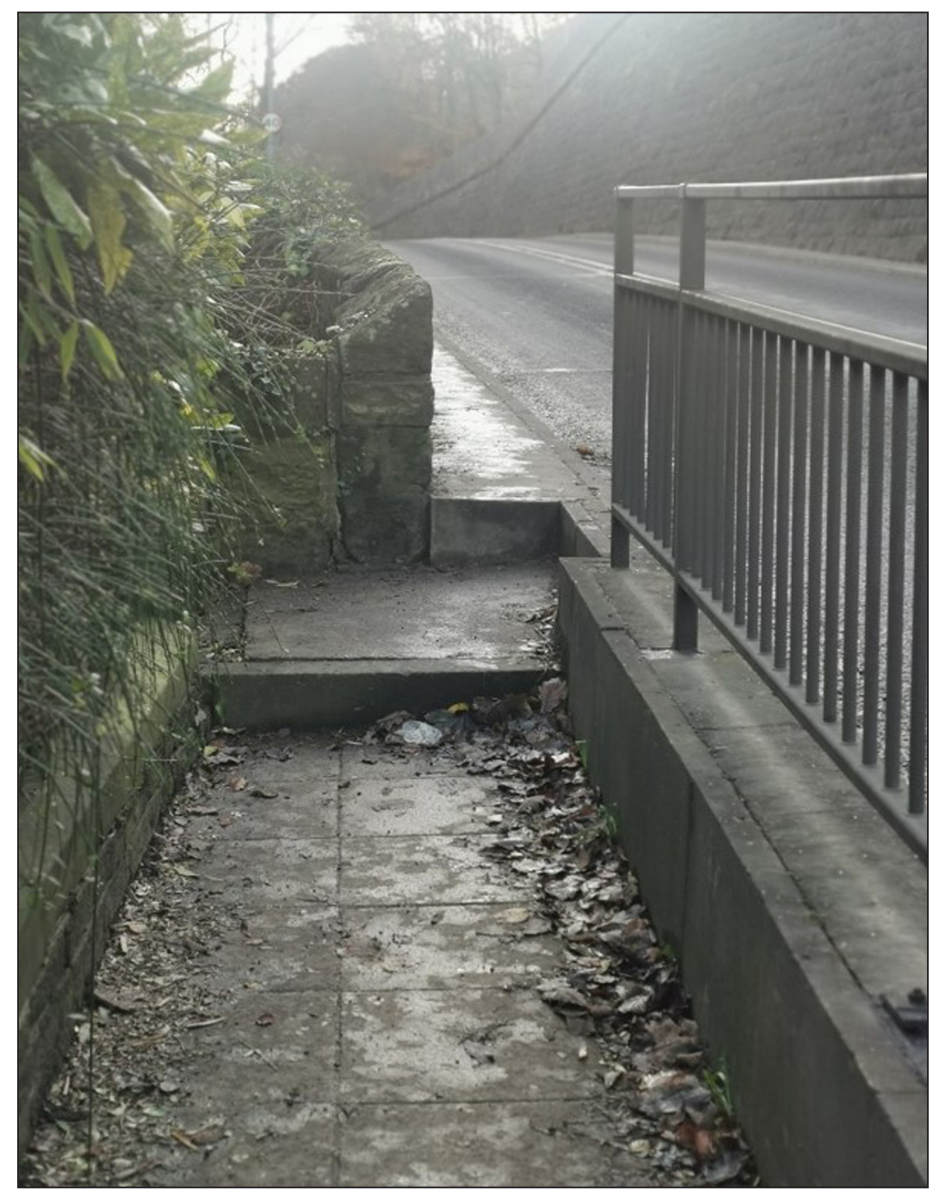

Figure 2: Inaccessible surface conditions.

If people are prevented from walking or cycling in these, or similar ways, then what are the justice implications? One option that people have in this case is to forego whatever activities the walking or cycling enabled. Alternatively, if they have the option, they tend to make the journey by public transport. This assumes, however, that public transport is both available and accessible, and either or both might not apply. Or, if they are able, people can make the journey by car or van. However, this last option pulls against efforts to reduce motor traffic and at best impedes the justice requirement to reduce harm of traffic. Yet, suggesting the activity is foregone could also be an injustice. Whether or not it is foregone, could be a complex question in some cases, but not in others. It would be difficult to maintain there is justice if people are excluded from everyday activities such as accessing basic services, education, employment or (pandemics notwithstanding) being with family and friends. If barriers to walking and cycling mean these activities can only be undertaken by using a vehicle, then justice might actually require that access to vehicles is facilitated. In this way, this situation creates a tension for mobility justice.

The tension related to mobility justice is greater than the problem that in such situations justice could appear to require facilitating vehicle use while simultaneously requiring reduction in vehicular travel. This is partly because not everyone can use a vehicle; for instance, they might not drive or have low incomes and lack substantial subsidy for vehicles. The tension 
is greater also because some important activities enabled by walking or cycling cannot be accessed by vehicle. Severance in walking environments which occurs close to home can prevent activities within neighbourhoods and even within a street. Appleyard and Lintell's (1972) famous study provides evidence of the extent to which this happens. In short, barriers to walking and cycling can create acute exclusion.

All of the above is an argument for transport policy and planning to prioritise removing severance for cycling as well as walking. There is quite a straightforward further argument for prioritising removal of all forms of severance preventing walking, and it is solely about capability. Many more people can walk either on foot or by using a wheelchair or other mobility aid (assuming conditions permit) than can cycle, meaning that it would not be enough to prioritise cycling without simultaneously focusing on walking.

\section{Conclusion}

Taking seriously the removal of severance for walking has quite profound implications for transport policy and planning, and will be a significant departure from much existing practise. We can give a brief illustration of the types of practical measures removing pedestrian severance might require. If (or where) there is limited space and so a competition arises between carriageway width and footway, then the footway would take priority. Pedestrian road crossings would need to provide enough time for anyone using them to cross safely even where this upsets traffic flows. Footways would need maintenance at least comparable with that given to carriageways, including treatment for ice in winter. There would also be a need for more investigation and resources given to measures to reduce crime affecting pedestrians. Detailed understanding of how to tackle severance in different places and contexts will require participatory planning, involving people who are, or who risk, being affected by severance. While such participation is widely recognised as vital in creating accessible spaces (see e.g. DfT (b) (2020)), there will need to be consideration of what this means for mobility planning processes. It will be apparent from this that removing severance for pedestrians will require actions which are at odds with planning informed by decision-making tools which attribute economic value to more and faster traffic. This is a not a unique challenge, and there is longstanding criticism that traffic favouring decision-making tools are themselves in tension with sustainability in mobility (Banister, 2008). As such, the arguments in this paper contribute to the debate on the boundaries which should be placed on the influence of those tools in decision-making. We should not underestimate the scale change in planning processes required to tackle pedestrian severance would bring. However, this level of focus on walking and accessibility for pedestrians is key to addressing central tensions facing sustainability and justice, and so is key to the realisation of a just mobility system.

\section{Competing Interests}

The author has no competing interests to declare.

\section{References}

Appleyard, D and Lintell, M. 1972. The environmental quality of city streets: The residents' viewpoint. American Institute of Planning Journal, 38(3): 84-101. DOI: https://doi. org/10.1080/01944367208977410

Banister, D. 2008. The sustainable mobility paradigm. Transport Policy, 15(2): 73-80. DOI: https://doi.org/10.1016/j.tranpol.2007.10.005

Beyazit, E. 2011. Evaluating social justice in transport: Lessons to be learned from the capability approach. Transport Reviews, 31(1): 117-134. DOI: https://doi.org/10.1080/01 441647.2010.504900 
Brand, C, et al. 2020. Road to zero or road to nowhere? Disrupting transport and energy in a zero carbon world. Energy Policy, 139: 111334. DOI: https://doi.org/10.1016/j. enpol.2020.111334

Bostock, L. 2001. Pathways of disadvantage? Walking as a mode of transport among low-income mothers. Health and Social Care in the Community, 9(1): 11-18. DOI: https:// doi.org/10.1046/j.1365-2524.2001.00275.x

Department for Transport (DfT (a)). 2020. Gear change, a bold vision for cycling and Walking. Available from https://assets.publishing.service.gov.uk/government/uploads/ system/uploads/attachment_data/file/904146/gear-change-a-bold-vision-for-cyclingand-walking.pdf.

Department for Transport (DfT (b)). 2020. The inclusive transport strategy - summary of progress. Policy paper. Updated 3 November 2020. Available from https://www.gov.uk/ government/publications/inclusive-transport-strategy/the-inclusive-transport-strategysummary-of-progress.

Dworkin, R. 2000. Sovereign virtue: The theory and practise of equality. Cambridge, MA: Harvard University Press.

EEA, FOEN. 2011. Landscape fragmentation in Europe. EEA report 2/2011. Available from https://www.semanticscholar.org/paper/Landscape-fragmentation-in-Europe.-JointEEA-FOEN-Jaeger-Soukup/1b8f10386310d81fbe71d586c7e7fee5a1377021.

Eisenberg, Y. et al. 2017. Planning walking environments for people with disabilities and older adults. In: Walking. Transport and Sustainability series. Bingley: Emerald Publishing Limited, 9: 187-209. DOI: https://doi.org/10.1108/S2044-994120170000009012

Figueroa Martínez, C. et al. 2019. Walking through deprived neighbourhoods: Meanings and constructions behind the attributes of the built environment. Travel Behaviour and Society, 16: 171-181. DOI: https://doi.org/10.1016/j.tbs.2019.05.006

Grigoratos, T and Martini, G. 2014. Non-exhaust traffic related emissions - Brake and tyre wear PM. (Joint Research Centre Science and Policy Reports) PM. EUR 26648. Luxembourg: Publications Office of the European Union. Available from https://publications. jrc.ec.europa.eu/repository/handle/JRC89231.

Harris, J. 1988. More and better justice. In: Bell, J. M. and Mendus, S. (eds.). Philosophy and Medical Welfare. 1st ed. Cambridge: Cambridge University Press, 75-96.

IEA. 2017. Energy technology perspectives 2017: Catalyzing energy technology transformations. International Energy Agency. Available from https://iea.blob.core.windows.net/assets/ a6587f9f-e56c-4b1d-96e4-5a4da78f12fa/Energy_Technology_Perspectives_2017-PDF.pdf.

Karlson, M and Mörtberg, U. 2015. A spatial ecological assessment of fragmentation and disturbance effects of the Swedish road network. Landscape and Urban Planning, 134: 53-65. DOI: https://doi.org/10.1016/j.landurbplan.2014.10.009

Mace, GM, et al. 2014. Approaches to defining a planetary boundary for biodiversity. Global Environmental Change, 28: 289-297. DOI: https://doi.org/10.1016/j.gloenvcha.2014.07.009

Mattioli, G. 2016. Transport needs in a climate-constrained world. A novel framework to reconcile social and environmental sustainability in transport. Energy Research and Social Science, 18: 118-128. DOI: https://doi.org/10.1016/j.erss.2016.03.025

Mattioli, G. 2017. "Forced car ownership" in the UK and Germany: Socio-spatial patterns and potential economic stress impacts. Social Inclusion, 5(4): 147-160. DOI: https://doi. org/10.17645/si.v5i4.1081

Mindell, JS and Saffron, K. 2012. Community severance and health: What do we actually know? Journal of Urban Health: Bulletin of the New York Academy of Medicine, 89(2): 232-246. DOI: https://doi.org/10.1007/s11524-011-9637-7 
Mullen, C. 2020. Governing a risky relationship between sustainability and smart mobility. In: Finck, M, Lamping, M, Moscon, V and Richter, H (eds.). Smart Urban Mobility - Law, Regulation, and Policy. MPI Studies on Intellectual Property and Competition Law. Berlin: Springer-Verlag. DOI: https://doi.org/10.1007/978-3-662-61920-9_2

Mullen, $\mathbf{C}$ and Marsden, G. 2016. Mobility justice in low carbon energy transitions. Energy Research and Social Science, 18: 109-117. DOI: https://doi.org/10.1016/j.erss.2016.03.026

Mullen, C, Marsden, G and Philips, I. 2020. Seeking protection from precarity? Relationships between transport needs and insecurity in housing and employment. Geoforum, 109: 4-13. DOI: https://doi.org/10.1016/j.geoforum.2019.12.007

Pooley, CG, et al. 2013. Policies for promoting walking and cycling in England: A view from the street. Transport Policy, 27: 66-72. DOI: https://doi.org/10.1016/j.tranpol.2013.01.003

Preston, J and Rajé, F. 2007. Accessibility, mobility and transport-related social exclusion. Journal of Transport Geography, 15(3): 151-160. DOI: https://doi.org/10.1016/j. jtrangeo.2006.05.002

Rogelj, J, et al. 2018. Mitigation pathways compatible with $1.5^{\circ} \mathrm{C}$ in the context of sustainable development. In: Global Warming of $1.5^{\circ} \mathrm{C}$. An IPCC special report on the impacts of global warming of $1.5^{\circ} \mathrm{C}$ above pre-industrial levels and related global greenhouse gas emission pathways, in the context of strengthening the global response to the threat of climate change, sustainable development, and efforts to eradicate poverty. Available at https://www.ipcc. ch/site/assets/uploads/sites/2/2019/02/SR15_Chapter2_Low_Res.pdf.

Sims, R, et al. Climate change 2014: Mitigation of climate change. Contribution of Working Group III to the Fifth Assessment Report of the Intergovernmental Panel on Climate Change. Cambridge: Cambridge University Press.

Verlinghieri, E and Schwanen, T. 2020. Transport and mobility justice: Evolving discussions. Journal of Transport Geography, 87. DOI: https://doi.org/10.1016/j.jtrangeo.2020.102798

Wadud, Z, MacKenzie, D and Leiby, P. 2016. Help or hindrance? The travel, energy and carbon impacts of highly automated vehicles. Transportation Research Part A: Policy and Practise, 86: 1-18. DOI: https://doi.org/10.1016/j.tra.2015.12.001

World Health Organisation. 2016. Ambient air pollution: A global assessment of exposure and burden of disease. Available from http://apps.who.int/iris/bitstr eam/10665/250141/1/9789241511353-eng.pdf?ua=1.

World Health Organization. 2018. Global status report on road safety 2018. Available from https://www.who.int/publications/i/item/9789241565684.

Yang, Y, et al. 2020. Towards a cycling-friendly city: An updated review of the associations between built environment and cycling behaviors (2007-2017). Journal of Transport \& Health, 14: 100613. DOI: https://doi.org/10.1016/j.jth.2019.100613

\begin{abstract}
How to cite this article: Mullen, C. 2021. Why Mobility Justice Means Prioritising Accessible Walking Environments. Active Travel Studies: An Interdisciplinary Journal, 1(1): 3, 1-9. DOl: https:// doi.org/10.16997/ats.1066
\end{abstract}

\title{
Submitted: 22 April 2021 Accepted: 19 May 2021 Published: 11 August 2021
}

Copyright: (c) 2021 The Author(s). This is an open-access article distributed under the terms of the Creative Commons Attribution 4.0 International License (CC-BY 4.0), which permits unrestricted use, distribution, and reproduction in any medium, provided the original author and source are credited. See http://creativecommons.org/licenses/by/4.0/.

Wu Active Travel Studies: An Interdisciplinary Journal is a peer-reviewed open access journal published by University of Westminster Press. 